\title{
Confesiones de un médium. Hacia la materialización del
} Baudrillard (1978: 10-2) no trabajo de campo tiene otro empeño que el de

Este trabajo participa de la tradición iconoclasta que caracteriza a la modernidad y que, como sugería prevenirse ante la posibi-

El presente artículo tiene la intención de devolver al primer plano las labores corporales y materiales que determinan el trabajo de campo. Siguiendo alguna de las propuestas de los estudios sobre la ciencia, Bruno Latour refiere la importancia que tienen para el contenido del conocimiento alcanzado las vinculaciones y desplazamientos materiales por los diferentes escenarios del trabajo de campo.

En el artículo utilizo las experiencias derivadas de una investigación realizada en los fraccionamientos cerrados de clase alta del Área Metropolitana de Guadalajara para ilustrar cómo la distribución material y simbólica del investigador por las locaciones del campo condicionan algunos de los descubrimientos producidos. El artículo suscribe, finalmente, la necesidad de enfocar la realización del trabajo de campo desde el paradigma epistemológico del realismo incorporado.

Palabras clave: trabajo de campo, materialidad, Bruno Latour, realismo incorporado, fraccionamientos cerrados.

- Investigador Titular A del Departamento de Ingenierías del Centro Universitario de Tonalá de la Universidad de Guadalajara. fercalonge@yahoo.es lidad de que cualquier aparato de representación aspire a capturar y a reflejar la realidad. En este caso el icono que pretendo discutir es el del secular intento de la ciencia por trabajar sobre el supuesto de un espejo de la naturaleza ${ }^{1}$ y la pretensión del observador por borrarse en el acto de la misma observación.

La Real Academia Española (DRAE, 2001) define médium como "persona a la que se considera dotada de facultades paranormales que le permiten actuar de mediadora en la consecución de fenómenos parapsicológicos o de hipotéticas comunicaciones con los espíritus". Como iconoclastas, tenemos que afirmar que el científico ha jugado a ser un médium, al satisfacer todos los criterios de la anterior definición. El científico está dotado de facultades paranormales que lo

I. Esta es la labor que Rorty descubre para la filosofía, entendida desde el siglo XIX como teoría del conocimiento subyacente a la ciencia (Rorty, 1995: 127-9). 
ubican en una dimensión diferente a la del sentido común, ${ }^{2}$ el cual caracteriza la capacidad corriente de percepción y de entendimiento. Sus formas perceptivas son extremadamente sensibles porque le permiten ver lo que la gente corriente no ve. Sus aptitudes son paranormales, porque taumatúrgicamente lo ubican en una posición cognoscitiva del más allá.

En función de estas habilidades extraordinarias se hace mediador para la aparición de fenómenos igualmente extraños. A través de su persona se nos presentan cristalinamente una serie de sucesos por entero ajenos a sus condicionantes y personalidad. Por ello, estos sucesos son asimismo parapsicológicos; su naturaleza es de un orden diferente a lo psicológico. Son sucesos-sucesos, no sucesos-concebidos o interpretados, es decir, son realidad en sí misma. Pero como científicos los hay no sólo naturales, como los atrás descritos que se anulan ante los sucesos naturales; también los hay sociales. Este tipo de médiums alcanzan no ya a ser mediadores de aquellos sucesos paranormales, sino a entablar comunicaciones con las ánimas. Así es como, a través de esa otra suerte de artes llamada 'Verstehem', ${ }^{3}$ pueden hacerse mediadores ya no de sujetos cotidianos y corpóreos, con sus necesidades y limitantes físicas y materiales, sino de sus mismos espíritus. El médium, cuando asume las dotes de científico social, es capaz de comunicar con lo más profundo de las almas y las conciencias con omisión de todos sus condicionantes corporales y físicos.

Como iconoclastas no podemos menos que preguntarnos por esos sortilegios que parecemos seguir en nuestro otro papel de científicos sociales. Corresponde así emprender una

2. Incluso un autor tan reflexivo como Bourdieu suscribe esta naturaleza paranormal del científico en tanto que ha de ubicarse en otro espacio que el entendimiento popular (Bourdieu, Chamboredon y Passeron, 1975: 28-30).

3. Para una brillante exposición de la tradición interpretativista frente a la positivista en ciencias sociales es todavía canónico el trabajo de Habermas (1988:8I-I20).

\section{6}


revisión autocrítica, reflexiva, sobre las propias mañas para hacer aparecer esos efectos ilusionistas de la generación del conocimiento. Para ejemplificar este tipo de $\operatorname{artes}^{4}$, tomaré la investigación que realicé entre 2009 y 2011 en el Área Metropolitana de Guadalajara acerca de las formas de vida propias de los fraccionamientos cerrados de clase alta.

\section{Una reflexividad materialista para abrir la caja negra}

Bruno Latour (1992, 2002 y 2005), de quien tomaré bastantes de las sugerencias a desarrollar, utiliza el término caja negra para referirse a una serie de operaciones desplegadas por los científicos, que sirven para ocultar los procesos contingentes que se alojan detrás de la generación del conocimiento, así como de su acumulación de prestigio y poder. Según Latour (2001: 362), cuando se constituye una caja negra, todos aquellos no científicos, los legos, solo pueden observar los resultados de la producción científica, ignorando completamente los mecanismos e intercesiones que la motivaron. De modo que cuanto más avanza la ciencia y su prestigio, tanto más opacos y oscuros se vuelven para el público general los procedimientos con que opera.

La ciencia alcanza a constituirse como caja negra porque oculta todos los procesos sociotécnicos que se vinculan a la generación de la realidad y del conocimiento. Todos los complejos ajustes y desajustes entre actores humanos, instrumentales y sucesos y entidades 'naturales' que tienen

4. La investigación estuvo auspiciada dentro del programa de formación de recursos de alto nivel de CONACYT y se desarrolló como apoyo postdoctoral en el Centro de Estudios de Género, Universidad de Guadalajara.Tuve la suerte de desarrollarla conjuntamente con la Dra. Manuela Camus Bergareche. La naturaleza de tan estrecha colaboración le da el sentido plural a las vicisitudes que se muestran en el trabajo de campo. El objetivo de la investigación era el de examinar las nuevas cotidianidades y prácticas espaciales que desarrollaban las clases medias altas y altas residentes en fraccionamientos cerrados de Guadalajara. 
lugar dentro del laboratorio (Latour, 1992: 77-90), todos los enrolamientos políticos y económicos externos al laboratorio y que lo hacen socialmente viable (Latour, 1992: 142-156), son omitidos como si el descubrimiento fuera una simple y directa relación del científico con su objeto. Las artimañas de los científicos naturales tienen un escenario muy bien demarcado: el laboratorio. Ese es el lugar donde despliegan el grueso de las asociaciones, permutaciones y materializaciones que les permiten aparecer, una vez que ha sido apartado de la vista pública, ese sentido no controvertido de la realidad. Por desgracia para nosotros, esa otra clase de médiums que somos los científicos sociales, no contamos con un espacio tan fácilmente clausurable. Nuestro laboratorio se encuentra allá afuera, en ese mismo territorio del tradicional objeto que con dificultades se intenta contener y amarrar. Sin embargo, también para el científico social el camino del prestigio y del poder es el mismo: ocultar las vinculaciones materiales y contingentes que hacen emerger los sucesos, y ocultar también las relaciones económicas y políticas que aportan relevancia social a los 'hallazgos'.

El empeño de Latour como antropólogo de la ciencia consiste en rescatar esa asociación bizarra entre lo artificial y lo natural del laboratorio, porque estima que es esencial para conocer el sentido de la realidad alcanzada y sus consecuencias sociales. Según va a señalar, todo el aparataje sociotécnico que desde fuera y desde dentro sostiene al laboratorio es lo que va a coproducir (junto con esos otros actores que se enrolan como 'naturaleza') los descubrimientos científicos y sus formas de aplicación (Latour, 2002: 173).

La labor de borradura es la que realiza el científico $a$ posteriori y que le conduce a sostener la lógica del descubrimiento independiente del descubridor y de todo su aparataje sociotécnico. Es el proceso donde se traducen los acoplamientos dudosos, los primeros test erróneos, las vinculaciones técnicamente ilegítimas, en un camino cierto 
Confesiones de un médium. Hacia la materialización del trabajo de campo

hacia el descubrimiento de la realidad. El proceso está también presente en la ciencia social y consiste en el escamoteo de toda la contingencia y dispersión en el campo hacia la mostración de una evidencia incontrovertible.

Alguien podría decir que estas advertencias de Latour han estado presentes en toda su integridad, particularmente dentro de las ciencias sociales. Asentada la diferencialidad de lo humano en lo simbólico, se hizo insostenible asegurar que el investigador podía acceder a la subjetividad o a los significados de sus investigados sin pretender modificarlos por su simple presencia (como otra subjetividad) (Giddens, 1993: 175) o por la interpretación que daba de los mismos (Gadamer, 1977: 331-8). Dentro de este terreno de lo humano, por ejemplo, es inevitable no suponer la competencia simbólica en el investigado que le lleva, a su vez, a reinterpretar sus respuestas y conductas anticipándose a las expectativas que se sospecha le está dirigiendo el investigador. Este último no puede permanecer ajeno, entonces, a estos juegos de las expectativas y las reflexividades recíprocas. Así -se agregará-, la historia de la reflexividad es dilatada en las ciencias sociales, como ese empeño por hacer conscientes las influencias y las mediaciones que, como investigador de lo humano, se imponen en el contacto y la mediación significativa con los investigados.

Si hay una disciplina donde la reflexividad ha sido una máxima operativa, esa es la antropología. No obstante, ese intento por controlar las interacciones que mantiene el antropólogo con su campo de estudio suele entenderse en su dimensión puramente intersubjetiva, de forma que se busca moderar la influencia y los posibles sesgos interpretativos que se establecen en la doble direccionalidad investigadorinvestigados (Aull Davis, 1999: 5-7). Así, por ejemplo, se hace un llamado a ser conscientes de las formas como la propia presencia del antropólogo en el campo colabora con la modificación o la dominación sobre las comunidades

Teoría y DEBATE No. 60 
colonizadas (James, 1973: 41-50; Sibeud, 2008: 105-10), de la manera como las concepciones compartidas por la propia comunidad científica pueden alterar o distorsionar las formas nativas de entender su existencia (Aull Davis, 1999: 6) o del lento proceso como el mundo intersubjetivo de la comunidad de estudio comienza a hacer mella y a ser concebido por el propio investigador (Leslie y Storey, 2003:120-7; Csordas, 2007: 107-115).

Sin embargo en enfoque que aporta Latour sobre el trabajo de campo es novedoso por cuanto supone mirar más allá del campo intersubjetivo de los intercambios significativos (el médium que tiene la capacidad para comunicarse con los espíritus), para ubicar esos encuentros en un campo de inter-objetividades (Latour, 2005: 280). Como bien señala el francés, la intersubjetividad sería imposible sin un campo intermedio de inter-objetividades repleto de instrumentos, espacios, cuerpos y objetos que devuelven a la investigación, al investigador y a los investigados toda su materialidad. De este modo, el descubrimiento científico que la antropología había reescrito mayoritariamente como intercambio significativo puede ser visto como un encuentro material en donde las condicionantes y los elementos de la locación son fundamentales para el sentido del fenómeno generado. El campo de inter-objetividades, con sus cuerpos, sus entornos, estilos, proximidades y asociaciones es lo que, a su vez, materializa la investigación y el conocimiento allegado.

En el trabajo de campo no escasean estos esfuerzos, y lo que siempre se había entendido como componente único en la producción de conocimiento -la observación, el registro, la reflexión, análisis y síntesis de los resultados- no puede concebirse sin todos esos trabajos materiales y corporales que distribuyen al investigador por las diferentes locaciones. El trabajar y dejarse trabajar por un determinado encuentro en el campo es fundamental para las experiencias que van a sostener la emergencia del conocimiento. Ese es el elemento 
Confesiones de un médium. Hacia la materialización del trabajo de campo

materialista que, junto con Latour, propongo considerar para enriquecer la máxima de la reflexividad en el trabajo antropológico.

Materializando el campo en una investigación en los fraccionamientos cerrados de clase alta en el Área Metropolitana de Guadalajara

Ser iconoclastas a pesar de uno mismo implica mostrar cómo mi desplazamiento por el campo, en la referida investigación sobre los fraccionamientos cerrados, obró la emergencia del particular tipo de conocimiento alcanzado. En ese campo, las bifurcaciones que había que abrir esforzadamente, o rehuir dándoles la espalda, condicionaron el modo como la realidad fue convocada, no de una forma anecdótica y casual, sino sistemática y recurrentemente.

Así, algunos encuentros del campo se generaron en las viviendas de los entrevistados, a veces en la antesala, como corresponde a una visita que no es del todo reconocida. Desde este lugar, la conversación giraba ineludiblemente sobre lo doméstico, que había de ser proyectado imaginariamente, pero también subrayado por ciertos gestos deícticos hacia el resto del hogar. En alguna ocasión, cuando la visita se prolongaba y se iba generando cierto acostumbramiento mutuo a sus condicionantes, la conversación sobre alguna estancia particular abría de repente para el entrevistado la necesidad de mostrarla físicamente y de señalar in situ los significados y experiencias que deparaba esa habitación. Ni qué decir tiene que ese acostumbramiento no se producía por una suerte de comunión de espíritus; tenía que trabajarlo a través de gestos de comprensión y confianza, remarcando mi acento español, en caso de que el entrevistado se mostrara orgulloso de algún antepasado de esta procedencia, o simplemente apelando a la satisfacción del estómago llevando unas buenas galletas que poder disfrutar durante el diálogo.

Teoría y DEBATE No. 60 
En estos casos, aquellas comunicaciones sobre lo doméstico que se compartían en la antesala de la vivienda cobraban vida al sostenerse y encarnarse en la particularidad que prestaba cada una de las estancias visitadas. Entonces, el lenguaje encontraba su perfecto asiento en un espacio de objetos, artefactos y prácticas.

Recuerdo que en otra visita al fraccionamiento de lujo por excelencia en Guadalajara, Valle Real, el desconocimiento previo no alcanzó a que se abriera siquiera la puerta de la casa. El hombre de negocios que entrevisté era demasiado celoso de su intimidad como para mostrarla en su despertar perezoso de un sábado por la mañana. Acaso tampoco era el lugar más determinante para lo que él quería mostrar de su identidad. Las preocupaciones de lo doméstico no casan bien con el orgullo de sí que mostraban algunos varones. Así que lo que comenzó frustradamente como una entrevista en un banco al exterior de la vivienda, se transformó en una oportunidad única para adentrarme en esos otros lugares decisivos para el sentido de sí del entrevistado; unos que se distribuían por el hervidero de lujo, frenesí y emulación que caracterizan a la Casa Club del fraccionamiento. En aquella ocasión rápidamente nos trasladamos a ese espacio colectivo y ahí comprendí que para adentrarme en la personalidad del individuo que tenía enfrente no tenía que desplazarme por las estancias de su hogar, sino por ese otro espacio de socialidad, opulencia y negocios: la mentada Casa Club. En ella la conversación dio un vuelco. Dejó de referirse indolentemente a la cotidianidad en la familia, para atropellarse en el recuento de una serie de relaciones, ascensos, empresas y éxitos que reverberaban por todas esas mesas, camareros obsequiosos, manjares, decoraciones doradas estilo 'neorococó' y hombres de negocios que componen la locación de la Casa Club. La satisfacción mostrada por recordar el éxito alcanzado y los esfuerzos requeridos resonaban más 
Confesiones de un médium. Hacia la materialización del trabajo de campo

fácilmente al interior del acaso más privilegiado enclave espacial de la ciudad de Guadalajara.

¡O qué decir de esas otras visitas a los fraccionamientos! Aquellas donde el encuentro, por estar compartido con el cuidado de los niños que se tenían al cargo, había de realizarse en alguno de los lugares para su esparcimiento, como la piscina, durante las clases de natación de los dos hijos de la entrevistada. En esa particular locación se pusieron de manifiesto las formas concretas de interrelación y socialidad que sostenían las mamás allí reunidas. Esas formas, tratándose de la clase alta, no se basaron en compartir relajadamente los espacios, sino, más bien, en una medición y cálculo de los detalles más ínfimos de la propia presentación ante la sociedad de madres. La piscina era el lugar donde sus identidades se hacían manifiestas a través de la demostración del orgullo provocado por los progresos acuáticos de los hijos, o a través de la propia exhibición engalanada por lujosas bolsas de playa, lentes oscuros o incluso en la forma de cirugías capaces de devolver la eterna juventud a una madre añada. Toda esa disposición de elementos dibuja una locación muy singular para su sociabilidad en esa piscina, alrededor de los consejos, las confidencias, las comparaciones y las críticas descuidadas entre las que pude situarnos como un elemento más.

De este modo, el saberme disipar a lo ancho de estos espacios del lujo fue posibilitando el que hiciera emerger las múltiples facetas de la realidad social y material que representan los estilos de vida y las identidades de las clases altas de Guadalajara. El acceso a estos diferentes matices no se produjo por una suerte de comunión o intercambio significativo que abrió inmediatamente la comprensión: la comprensión tuvo que materializarse a través de toda una serie de trabajos, reacomodos y puestas en sintonía con los elementos y actores encontrados a lo largo de las diferentes locaciones del campo. De modo que saber maniobrar 
por alguna de ellas significó poder acceder a uno de sus determinados sentidos. Y al contrario, la incapacidad para conducirme prácticamente por otras locaciones implicó el cierre de los significados que sustentaban. Así, una de las realidades sociales vividas por estas clases que no pude recrear fue la de la fraternidad y los negocios sostenidos, mayoritariamente por los hombres, a través del juego del golf. Durante el trabajo de campo, fui incapaz de vincularme a estas locaciones y recuperar el sentido que poseían para las clases altas estudiadas.

Pero, sin duda, antes de lo que aconteció al interior de estos diferentes espacios, lo crucial para la investigación fue posibilitar la entrada misma al campo. Con motivo de un acto académico tuve un encuentro con otro investigador que me ayudó a posicionar las circunstancias prácticas y materiales que facilitaron mi investigación. Hay que decir que la realización del campo se avino con una naturalidad tal que me tuve que forzar a mí mismo a comprender la dureza y laboriosidad que supondría el convocarlo. Por eso el encuentro con este investigador fue tan significativo para mí. Intentando realizar un trabajo similar, lo más relevante que me compartió fueron las grandes dificultades que encontraba para acceder al campo. Inmediatamente, toda una gran capa de recuerdos y sensaciones mantenidos en segundo plano (latentes) se reacomodaron a través de él, mostrándome la razón de ser de aquella naturalidad de mi acceso: él es mestizo y pertenece, por tanto, a ese sistema de diferenciaciones y discriminaciones sociales que apuntala buena parte de mis entrevistados. Su tez, acaso su acento, lo ubican en un escalafón desde el cual no pudo ser el emisor de preguntas e inquisiciones personales para aquellos que se encontraban en posiciones más elevadas. Él, como mestizo, es partícipe de una parte del problema que quería investigar (el clasismo de los estratos altos), lo cual dificultó enteramente su labor. Yo, por el contrario, soy 
español, y por mi presencia y mi ser, me ubiqué en un afuera de las interacciones clasistas tapatías, las cuales, además, servía para afirmar, pues me posicionaba en el afuera de una extracotidianidad que remite a los orígenes étnicos y sociales de unas clases altas donde la alcurnia abreva del criollismo. Como español, serví como un representante de la razón de ser que estas clases tienen para sostener su predominancia social.

Entonces, tras el encuentro con este alter pude comprender buena parte de la naturalidad con que me fui acoplando por los diferentes espacios de mi investigación. Su revelación sirvió para que alineara todas aquellas experiencias y recuerdos de segundo plano del campo con las del primero, de forma que pude resituarme como el elemento detonador de las confidencias y la exposición de las trayectorias vitales de estas capas sociales neocriollas. Recordaba entonces que mi tez blanca resonaba con esa tez blanca de los entrevistados o sus ancestros, y que mi acento les devolvía al recuerdo vivido o imaginado de unos orígenes españoles que representaban la antecámara o el detonante para el recuento del resto de sus discursos identitarios. En ocasiones pienso que yo dejé de ser el elemento protagonista y activo en la convocatoria del campo y la investigación, para ser acomodado por cada uno de mis entrevistados en sus salones, sus cocinas, sus parques, y hacer de mí una excusa para narrarse la historia de su predominio social. En este punto, tanto mi colega investigador como yo ocupábamos la misma ubicación dentro del espacio comunicativo que trazan los médiums para llamar a sus espíritus. Subjetividades inquisitorias que buscan una suerte de comunión simbólica con las almas que invocan. Sin embargo, en tanto que sujetos encarnados y posicionados en campos cruzados por diferenciaciones prácticas y materiales no podíamos situarnos en emplazamientos más alejados. Él, sintetizando a todos los elementos humanos mestizos sobre los cuales se 
alzaban los entrevistados. Yo, acercando a mis entrevistados al origen desde el cual organizaban su hegemonía.

Pero estas artes para el ilusionismo o la disipación a lo largo del campo no sólo se refieren a cómo ese campo se concentra en unos determinados descubrimientos. También indican los bordes donde el campo se desvanece hacia lo indiferenciado de otras realidades por estudiar. Sin embargo, nuestro campo, no deja de decantarse contra el telón de fondo de esos otros posibles que se disgregan. Los fraccionamientos cerrados de clase alta, en sus arquitecturas, jardines y facilidades adquieren su sentido contra el telón de fondo de toda la otra realidad urbana de Guadalajara. El sentido de su primacía lo adquieren al ubicarse como modelos materiales de lo que casi el grueso del resto de la ciudad aspira ser: espacios de la opulencia y exclusividad, admirados desde el resto de las posiciones de la trama urbana.

De modo que su exclusividad como modelo -cristalizada en su orden, en la abundancia de espacios y habitaciones, de lugares recreativos, de automóviles del año-solo destaca en su exactitud cuando se la compara con la exclusividad como promesa y aspiración que es ofrecida a la mano del resto de los ciudadanos. Aquí, haber aprovechado la ocasión de desplazarme a esos otros lugares de la ciudad, haber desbordado el campo, me ayudó también a comprenderlo mejor. Así es como tuve la oportunidad de visitar otros fraccionamientos que hacían el día a día de las capas populares de la población tapatía. En desarrollos como UrbiQuinta, Santa Fe o Chulavista pude comprobar esa imitación impotente de la distinción que implica el imponer la exclusividad a través de una barda que cierra el fraccionamiento.

Urbiquinta, Santa Fe y Chulavista también son exclusivos porque, a imitación de Valle Real, Rancho Contento o El Palomar (fraccionamientos de clase alta), también disponen de un muro que restringe los accesos. Sin embargo, su 
escasez de espacio y de zonas verdes, la existencia de lotes y viviendas ya abandonadas, la evidencia de unos pobres materiales desmoronándose, las pintadas y la suciedad de sus calles establecen un contrapunto irónico y sufrido cotidianamente para la verdadera exclusividad, la 'auténtica', la que representan los deseados fraccionamientos de clase alta. Este desplazamiento mío a estos posibles campos de los desarrollos habitacionales de clase baja me permitió comprender mejor la posición y el sentido de preponderancia que cobraban los otros espacios de la verdadera distinción de la clase alta.

Y como no puede dejar de suceder, tampoco faltó la prestidigitación que me permitió aparecer a través de muy concretas condiciones por los fraccionamientos de clase baja. A Santa Fe, en concreto, llegué en calidad de mero observador durante la realización de una serie de asambleas de vecinos para la expresión de quejas y problemas del conjunto habitacional. Después de un breve recorrido por el fraccionamiento llegamos al salón donde tendría lugar la reunión. Intentando atenuar mi interferencia, ubicándome cautamente en sus asientos posteriores, pude registrar el sucederse de las protestas de los vecinos, pero también de sus susceptibilidades y sospechas sobre la esterilidad de la convocatoria. Sin ser este mi campo, con la sola intención de probarlo como contrapunto explicativo a los fraccionamientos de clase alta, procedí según lo acostumbrado a borrarme como observador visible en los últimos asientos del salón.

Una disipación similar me ayudó a perfilar el sentido relacional de la apropiación que surgía de los fraccionamientos de clase alta. Pude llegar a aprehenderlo con la realización de cinco entrevistas suplementarias dentro de algunos fraccionamientos cerrados de clase media. La visita a estos espacios permitió, por contrapunto, refinar el sentido de apropiación que las clases altas realizaban de sus entornos. El visitar estos desarrollos al norte de Huen- 
titán me permitió acceder a los espacios estandarizados que la inmobiliaria pone a disposición de un tipo humano supuestamente prototípico de la clase media. Viviendas, avenidas y cajones de estacionamiento homogenizados, que aguardaban ser ocupados y personalizados por familias concretas. Observé que esta prefiguración del espacio suscitaba comportamientos de frialdad y desapego respecto al lugar de residencia, los cuales impedían el asomo de un sentido fuerte de pertenencia, propiedad e identidad; actitudes que sí pude advertir en los fraccionamientos de clase alta. Así, mientras que en los fraccionamientos de clase media el espacio ya dividido, planificado y construido imponía serias limitantes a recibir la proyección espacial e identitaria de las familias, los de clase alta ofrecían todas las oportunidades para hacerlo. En tanto que para estas familias de clase media la renuncia a algunos de sus proyectos vitales ${ }^{5}$ dentro de la estrechez y estandarización de sus viviendas es una obligación, para las de clases altas todas las posibilidades de materializar una apropiación plena del espacio existen. La posibilidad de elegir fraccionamiento según el carácter de las propias familia; la de contar con lotes baldíos de grandes dimensiones; la de ser asesoradas por arquitectos trabajando ex profeso para ellas; y la de levantar en piedra y ladrillo la estructura física que albergará sus necesidades y proyecciones futuros. Todas, posibilidades que hacían que el sentido de pertenencia e identidad con el hogar fuera muy destacado. Por este contraste con otras condiciones de apropiación, por esta breve disipación por otros campos posibles de investigación, pude ubicar otro contrapunto con el cual entender la orgullosa identificación que me mostraban mis familias de clase alta con los espacios de sus viviendas y fraccionamientos. 
De tal suerte, fueron las diferentes maniobras que me llevaron a acceder a los variados espacios de la producción y reproducción de las clases altas en Guadalajara, lo que suscitó el que pudiéramos todos juntos, investigador, espacios y habitantes, hacer asomar el significado que nuestras vidas adquieren por el encuentro; así, mi propio significado como investigador postdoctoral que buscaba una piedra de toque definitiva donde poner a prueba ciertas hipótesis sobre el espacio y la identidad, así también el significado de los lugares por cuanto contienen un cierto aire de estilo que define sus caracteres diferenciales, así, finalmente, el significado de éxito y diferenciación social que exhibieron las vidas de las familias entrevistadas. Si hubo acceso a los diferentes vericuetos del otro, esto fue no por una súbita comunión de los espíritus, no sólo por una ampliación del círculo hermenéutico derivada de los intercambios y análisis simbólicos, sino, fundamentalmente, a través de todos los trabajos $^{6}$ que facilitaron nuestros encuentros físicos y corporales.

\section{Remontando la desmaterialización materializando el lenguaje}

Sin embargo, si nuestro propósito es rematerializar el trabajo de campo para que emerjan los condicionantes para la aparición del conocimiento, un importante banco de

6. Debo hacer notar el uso intencionado del plural de la palabra trabajo para resumir la forma de la inserción en el campo. El plural no solo denota el sumatorio de las labores que activamente hay que realizar para acceder al campo, sino sobre todo el sentido de penalidad y de afección que retorna o rebota sobre el investigador como resultado de esos intentos y esfuerzos. Ese sentido fue el que, por ejemplo, le dio Hesiodo (1979) a su obra Los trabajos y los días. Aquí, en la descripción que da Hesiodo a su hermano Perses no está presente únicamente el recuento de las actividades agrícolas propicias, sino, más bien, el sentido de moralización y maduración que gana el trabajador a través suyo.Así, la obra es una especie de odisea para la autoexperimentación y el autodescubrimiento a través del trabajo. Ese es el sentido como el campo afecta y moraliza al investigador.

Teoría y DEBATE $@$ No. 60 
trabajo lo tenemos en todos los procesos que conducen a las experiencias y materialidades del trabajo de campo hacia su traducción a fórmulas lingüísticas. Son estos los procesos que refuerzan el papel del investigador como médium capaz de comunicarse con los espíritus. Y es que desde el propio campo hasta el procesamiento y análisis de los resultados y vestigios se ponen en marcha unos mecanismos de codificación y traducción que tienden a realizar una transformación lingüística y simbólica de las experiencias de todo orden allegadas. Es justo esa la labor de la metrología que Latour destaca como propia de las ciencias sociales y que comporta la estandarización de los fenómenos y de los casos particulares hacia la formación de las grandes categorías de análisis y de funcionamiento de lo social (Latour, 2005: 320-2). A través de ese proceso intermedio de codificación los distintos sucesos quedan esquematizados hacia la conformación de una clasificatoria y tipología.

Hay que agregar que en ciencias sociales esta metrología, que opera en ocasiones inadvertidamente, se expresa de manera particular bajo la forma de símbolos y registros lingüísticos. Desde la simplificación apenas consciente de todas las experiencias vitales y de toda la alquimia de los intercambios corporales ocurridos a los registros lingüísticos del cuaderno de campo, el proceso de descorporeización y de desmaterialización del investigador está puesto en funcionamiento. De este modo, las vinculaciones y las distribuciones materiales del investigador por el campo quedan resumidas en su expresión simbólica, de forma que se da un paso casi definitivo hacia el espacio incorpóreo del conocimiento. El mismo proceso vuelve a ponerse en marcha cuando toda la complejidad de la entrevista -dentro de la cual, como espero haber demostrado, el lugar, sus elementos y pliegues son actores fundamentales- queda igualmente reducida y simplificada a una transcripción de los intercambios exclusivamente lingüísticos. De forma que no quedando 
Confesiones de un médium. Hacia la materialización del trabajo de campo

más que palabras después de toda esta labor intermedia de codificación, transubstanciación y estandarización propia de la metronomía, es más fácil producir el efecto de estar comunicando sin mediación con las profundidades de las almas de una cultura, un grupo social o un individuo.

Parte de la clave para remontar la desmaterialización del trabajo de campo viene de la mano de una consideración materialista y pragmática del lenguaje. Si consideramos el lenguaje como materia, tendremos un elemento más que nos ayude a recuperar aquellos condicionantes materiales del trabajo de campo para la aparición del conocimiento. Esta tentativa ya la mantuvo Bakhtin en su análisis materialista del lenguaje al sostener que toda comunicación representa una interacción entre las condiciones materiales y simbólicas de los diferentes grupos sociales en pugna y confrontación (Voloshinov, 1976: 34). Para esta primera escuela marxista de análisis del elemento lingüístico el signo no dejaba de participar de esa misma realidad conflictiva que escenificaba la lucha de clases. La propuesta la retomó Barthes (1987: 127-9) al suscribir el concepto sociolecto para rescatar un análisis del habla en términos de poder. Desde esa perspectiva, existen una forma y estilística propias del habla de cada una de las clases evidenciadas; sin embargo, una escala diferenciada de las predominancias sociales. Tanto en uno como en otro caso, se intentaba rescatar al signo lingüístico del repliegue sobre su propio sistema y ubicarlo dentro de toda la conflictividad social.

No obstante, en la medida en que estas aportaciones devolvían la materialidad del lenguaje a través de su intermediación por los grupos o clases sociales, siempre se corría el riesgo de retroceder a esa imagen de lo social como campo conflictivo, sí, pero un campo conflictivo desentendido y retirado de todos sus condicionantes físicos y materiales, es decir, como mero espacio de las comunicaciones intersubjetivas. La recuperación definitivamente materialista del 
lenguaje va a venir, sin embargo, de parte del pragmatismo y su recuperación contemporánea por los estudios acerca del cognitivismo situado.

Desde esta escuela, Johnson y Rohrer (2007: 21) recuerdan cómo la cognición, de la cual el lenguaje sería uno de sus últimos desarrollos, aparece como "el proceso encarnado por el cual un organismo se encuentra en constante adaptación para utilizar de la mejor manera posible las potencialidades más estables de un entorno en constante cambio". De esta forma, se ha desarrollado la sugerente propuesta de considerar al lenguaje como una representación, por medios sígnicos, de las orientaciones motrices que embargan y direccionan al organismo dentro de su entorno (Lakoff y Johnson, 1999: 43). De esta forma, la cognición y sus formas más desarrolladas como el lenguaje tendrían una función sustancial para la orientación de los organismos, incluidos los humanos, en unos ambientes ricos en posibilidades para la supervivencia.

Dentro de este esquema básico el lenguaje aparece como una solución evolutiva idónea cuando la adaptación implica procedimientos complejos de coordinación ya no solo organismo-medio, sino organismo-organismo-medio. Es decir, el lenguaje posee una virtualidad eminentemente social para la coordinación de una asociación de individuos en su proceso de adaptación al medio. Como señalaban Maturana y Varela (1984: 144), el lenguaje representa el medio por excelencia para que los individuos puedan sostener la coordinación de sus conductas cooperativas dentro de su inserción conjunta en el medio. Ahora bien, aunque el lenguaje incluso pueda prestar, evolutivamente, la capacidad de la reflexión sobre sí, de forma que el signo fuera objeto de representación para otro signo, sin embargo, no hay que hacer seguir a esta capacidad de un cierre de dominios: el mundo mental lingüístico frente al mundo de la realidad exterior. Aunque el signo pudiera referirse a 
otro signo, iniciando esta capacidad reflexiva del lenguaje, sin embargo, su orientación natural ${ }^{7}$ es siempre el medio y sus estímulos hacia los cuales siempre estuvo indicando. Por eso el lenguaje y la conciencia no están dentro del sujeto (Maturana y Varela, 1984: 154), sino justo en medio de la empresa adaptativa que coordina una asociación de individuos respecto a un ambiente.

Esto tiene consecuencias fundamentales para la comprensión de los hechos lingüísticos, de esa parte de la serie de comunicaciones que podemos captar en la interacción social que tiene lugar en el trabajo de campo. Desde esta perspectiva, el lenguaje siempre va a estar remitiendo a una forma particular de orientación en un espacio tanto material como social. Esto hace señalar a los propios Lakoff y Johnson que la mayoría de las enunciaciones lingüísticas puede ser interpretada como metáfora orientacional, es decir, una expresión que implica siempre un espacio y un tipo particular de orientación corporal dentro de él (Lakoff y Johnson, 1986: 50). Precisamente el hecho de que el sistema sensorial y motriz esté en la base de la aparición de las más básicas capacidades cognitivas permite, a través de su complejización, que las categorías básicas del lenguaje posean esa misma naturaleza orientacional.

Así pues, la comunicación con los espíritus que era el culmen de las habilidades del médium es mucho más que una comunicación con los espíritus, y debe remitir inexcusablemente a las formas en que esa comunión de espíritus se está esforzando por realizarse social y materialmente dentro de determinados mundos reales compartidos. Por lo tanto, el tipo de información que tenemos cuando estamos ante esa reducción de la experiencia del campo que es la transcripción, no es tanto una serie de imágenes que los

7. Sin comillas, puesto que el lenguaje se originó como una respuesta evolutiva más en el proceso de adaptación al medio. 
sujetos y grupos sociales se hacen sobre sí mismos y sobre su mutua relación, sino, fundamentalmente, una indicación de las estrategias pragmáticas que desarrollan para hacerse dentro de mundos tan sociales como materiales. Aquí el truco de prestidigitación que supone simplificar una experiencia de campo en una cadena de hechos lingüísticos debe ser seguido por otro truco, en sentido inverso, que retorne toda su dimensión de realismo incorporado al uso del lenguaje.

Nuestra investigación se rematerializa cuando aspiramos a rescatar de todo el complejo de enunciaciones no un sistema de diferencias intersubjetivas, sino la serie de orientaciones espaciales concretas de todos los sujetos implicados en el campo. Dentro de la descripción del sujeto moderno, siempre tuve predilección por el retrato que MacPherson (1970) hizo de la individualidad posesiva. Bajo su perspectiva, dicho tipo humano era concebido como un sujeto aislado y encerrado dentro un campo propio de posesionamientos. En este círculo interior, el sujeto podía reconocerse a sí mismo y a sus intereses para luego, en las condiciones de mercado, salir a él para defenderlos a través de una serie de transacciones de naturaleza exterior respecto a otros individuos. Esta definición, que se basa en una serie de tesis sobre la relacionalidad interindividual, para mí siempre tuvo, sin embargo, un componente espacial y material tan básico como imborrable.

Buena parte de los relatos que me compartían mis entrevistados reproducían este mismo esquema de cierre y clausura identitaria que descubrió MacPherson. Así, adoptando esta estrategia de considerar el lenguaje en su función espacialmente intencional, quise comprobar cómo esas formas de autodescripción tenían un soporte por entero material. Así, pude observar cómo los espacios de la vivienda, del fraccionamiento cerrado y del resto de la ciudad abierta sostienen en su dimensión más material esa 
forma de concebirse el individuo moderno. Todo el empeño que ponían los sujetos de estas clases por clausurar sus espacios vitales, sus viviendas, sus fraccionamientos; por dejar afuera los elementos perturbadores y amenazantes, y poder constituir una interioridad para el reconocimiento y el disfrute de sí mismos era enteramente evidente no como categoría de análisis para la filosofía política, sino como una práctica directamente material (Calonge, 2013: 36).

La vivienda se convierte en ese espacio del reconocimiento y la intimidad porque sus espacios permitían la emergencia corporal de un sujeto moral responsable de sí mismo. Hacía, por ejemplo, que los padres pudieran descansar después de las tensiones del externo y mercantil mundo de los negocios en la comodidad de la sala de televisión, en la propia recámara o en la bien ganada soledad del propio despacho de la casa. Lejos de las miradas y expectativas externas, podían relajarse en la recuperación del 'sí mismo'. La vivienda permite también que, con sus múltiples ocupaciones de jardinería, de reparaciones o instalaciones, el hombre prolongue el proceso de su propia domesticación, haciendo de él siempre un sujeto laborioso y útil.

También en la vivienda la mujer aprende a reconocerse orquestando las labores del cuidado, vigilando con detenimiento las idas y venidas de los diferentes miembros del hogar a la mesa, con motivo del desayuno o de la cena, o ubicándose como sujeto estético, pensando y concibiendo cómo hacer de la decoración una segunda piel, expresiva, para todo el hogar. Pero también en la vivienda, segura y resguardada bajo los muros del fraccionamiento cerrado, la mujer es posesionada por el varón, quien puede salir tranquilo de viaje de negocios sabiendo que nadie amenazará su propiedad y a los suyos.

Finalmente, la vivienda es el espacio reservado y controlado para que los niños vayan forjando su carácter como futuros sujetos responsables de sí mismos. Aquí el 
caballo de batalla es enfrentar la que se consignaba como la tendencia natural de los niños: el divagar. Frente a esta tendencia, y bajo la lógica de que cada actividad tiene que quedar regulada por el espacio de una sola habitación, los niños aprenden a moralizarse centrándose exclusivamente en cualquiera ocupación que estén realizando al momento: el descanso, la comida, el estudio y también las diversiones. Conteniendo y haciendo previsibles los espacios, los padres pueden hacer previsible el carácter de sus hijos, quienes en un futuro tomarán su relevo exitosamente, en ese mundo exterior de los intercambios mercantiles.

De este modo fue como pude sostener que la formación de la individualidad posesiva liberal no es una cuestión de simple comunicación o autocomprensión simbólica; es, más bien, una labor obrada corporal y materialmente, mediante la cual unos organismos aprenden a hacerse regulares como individuos en pos de su posterior vinculación con otros espacios, como el de los negocios, donde la laboriosidad, la concentración, el esfuerzo, la superación o la responsabilidad serán las actitudes requeridas.

Con todo, esta forma de entender materialmente el lenguaje me sirvió asimismo para insertar de una manera más fundamental la relación de apropiación de los individuos de las clases altas con sus espacios vitales. Aplicando las tesis de Lakoff y Johnson (1986), pude comprobar cómo la forma con que los sujetos se refieren a sí mismos tiene fundamentales connotaciones espaciales que pudieron ser evidenciadas en la realización del trabajo de campo. Sin ir más lejos, el propio sentido de paz y tranquilidad que aparecía ampliamente citado dentro de las entrevistas como la motivación para irse a vivir a un fraccionamiento cerrado posee un componente espacial ineludible, toda vez que viene de la mano de la necesidad de asegurar la protección propia frente a una ciudad abierta que se siente y vive como un espacio caótico y riesgoso: desde el ruido a los congestiona- 
mientos viales, los accidentes de tráfico o a la posibilidad de ser víctima de algún asalto o secuestro. La sensación que los miembros de estas clases experimentan sobre sentirse expuestos a cualquier acontecimiento desagradable en las calles de la ciudad tiene su contrapunto con la experiencia de la tranquilidad asegurada en la construcción de la vivienda y el fraccionamiento, y en la interposición de otros tantos filtros y barreras a lo incierto.

Los controles de seguridad del fraccionamiento, la videovigilancia, los patrullajes, pero también las alarmas de las viviendas son otros tantos mediadores materiales para forzar el sentido de la clausura y distancia sociales. Fuera del fraccionamiento, estas clases altas disfrutan de la interposición de semejantes mediadores y barreras en las plazas comerciales, en los clubes privados o en las escuelas de pago a las que asisten sus hijos. En todos los casos, las características de estos espacios reflejan las formas que tienen estas clases de construirse simbólica y físicamente en el resguardo de sus personas, propiedades y estilos de vida, pero, al mismo tiempo, en el rechazo y la separación del resto de las realidades que componen a una ciudad como Guadalajara.

Esta forma de rescatar lo material del terreno de las distinciones sociales que aparecen en muchas de las enunciaciones de las clases altas se puede igualmente utilizar en la forma como refieren su crecimiento y desarrollo identitarios. Aquí se puede utilizar el concepto de trayectoria identitaria que, como nos aconsejarían considerar Lakoff y Johnson (1986), posee un sentido tanto simbólico como espacial, porque trayectoria no únicamente se refiere a los pasos sucesivos que han seguido las familias hasta la obtención y el mantenimiento del prestigio, sino también a los propios desplazamientos y asentamientos espaciales exhibidos a lo largo de los años. Así, el componente espacial de estas trayectorias del éxito describe un patrón que puede considerarse prototípico.

Teoría y DEBATE $@$ No. 60 
Los esposos de muchas de esas familias nacieron en familias a su vez acomodadas, provenientes de la propia Guadalajara o de otras ciudades de la República. Sin embargo, su camino de emancipación y formación de la propia familia hubo de seguir un proceso que recreó o, incluso, amplió su situación pasada. Por ello es frecuente observar a la recién formada pareja yéndose a vivir a un departamento más o menos amplio, ubicado en las inmediaciones de alguna de las familias de origen. Aquí nos encontramos al núcleo básico de esta futura familia en expansión y crecimiento social y espacial. Desde esta posición inicial, el desarrollo propio va a significar un proceso de creciente dominio y disfrute espacial. Cuando llegan los hijos y van fraguando los negocios o aumentan las remuneraciones (normalmente) del esposo, corresponde dar un salto a una vivienda en propiedad, una que pueda acompañar el crecimiento de la familia. Si el éxito se da rápidamente, la familia puede adquirir dicha casa unifamiliar en la misma colonia acomodada donde ya vivían, pero si este viene lentamente, en ocasiones se observa a la familia desplazándose a un fraccionamiento más modesto pero con posibilidades de construir una vivienda independiente.

Es frecuente observar una multiplicación de los estadios hasta la situación final que encontramos al momento de realizar el trabajo de campo. Estos estadios muestran el empeño de la familia por hacer que los espacios de sus hogares no solo secunden lo más básico y fundamental de la reproducción, sino otra suerte de comodidades y posibilidades vitales que exhiban un estilo de vida ampliado. Es así que se entiende como 'necesario' que cada nuevo hijo tenga su propio dormitorio, pero, dentro de ese plus que configura la vida de la clase alta, comienzan a añadirse otras tantas dimensiones espaciales en la forma de estudios, cuartos de baños suplementarios, salas de recreación, chimeneas, acuarios, habitaciones de huéspedes, habitaciones 
Confesiones de un médium. Hacia la materialización del trabajo de campo

para el gimnasio, etcétera. Así se van sumando las mudanzas según se acumulan las necesidades y las exigencias propias de unas clases en crecimiento y expansión. Esto tiene un reflejo espacial muy claro en casas cada vez más amplias, con un mayor número de cocheras, mayor espacio para el jardín y, también, en hogares que han alcanzado ya el suficiente nivel económico como para comenzar a sentirse celosos de su propia condición y seguridad y sentir la necesidad de retirarse a un fraccionamiento cerrado de clase alta.

De esta forma, si queremos hacernos una idea lo más exacta posible de la identidad de estas familias, en lugar de atender exclusivamente a la autoreferencialidad del lenguaje y constatar qué dicen sobre ellas y su relación con el resto de clases sociales, mejor haríamos en reinscribir ese lenguaje en el espacio de la ciudad, y en observar cómo esta va indicando extensiones de terreno cada vez más amplias, viviendas cada vez más vastas, complejas y resguardadas. De modo que cuando en el análisis estuviéramos ante un registro lingüístico, el esfuerzo habría de ir hacia rematerializar las condiciones de su inscripción, hacia recuperar aquellos espacios físicos y sociales dentro de los cuales hay un sentido práctico de adaptación y significación. Remontando de esta manera el proceso de desmaterialización es cómo podemos estar de vuelta en la importancia crucial que tiene el espacio y nuestra inserción como investigadores encarnados para la constitución del conocimiento.

Conclusiones: el campo como recreación

de mundos de vida

Después de lo expuesto con anterioridad parece claro que la postura por la que abogo a la hora de describir el proceso de investigación está lejos del paradigma de la representación en donde el investigador aspira a reflejar en su trabajo la existencia y disposición de ciertos fenómenos externos.

Teoría y DEBATE No. 60 
Restituir ese entorno material del laboratorio o del trabajo de campo que da acceso a la realidad implica restituir las vías que ponen en relación al médium con sus espíritus. Para que los espíritus pudieran comunicarse, antes era necesario un campo de inter-objetividades fundacional. Con la inclusión de los mediadores, físicos, pertinaces, se tienden los puentes que permiten hacer circular la referencia y rastrearla desde los distintos escenarios de emergencia de la prueba hasta los dispositivos que se encargan de traducirla hacia la dirección del conocimiento (Latour, 2002: 69).

Sin embargo, si la labor del investigador ya no es presentar espejos para reflejar diáfanamente la realidad, ¿cuál habrá de ser entonces? Para dar con la solución propongo que sigamos la lectura que realiza Ricoeur (2004) de la mímesis poética de Aristóteles. Para Aristóteles, la mímesis no es una simple copia de alguna entidad verdadera y exterior. Al contrario, la mímesis se compone de dos elementos: por un lado, comporta un sentido de construcción, en este caso de la trama poética (mythos); por otro lado, comporta un sentido de imitación (Ricoeur, 2004: 80-1). Como construcción de la trama, la mímesis implica necesariamente una actividad, una acción explícita que está muy alejada de la tradicional pretensión de la ciencia de no modificación del objeto, de simple reflejo suyo. La mímesis implica una actividad explícita de parte del poeta -en Aristóteles- o del científico -en nuestro caso- para recrear el acontecimiento. Ahora bien, junto a este movimiento activo de la construcción del mythos, la mímesis también implica un elemento de imitación, pero imitación no como copia o reflejo. La imitación para Aristóteles supone una recreación diferenciada respecto a una supuesta condición originaria del fenómeno. Al obrar la imitación se introduce siempre un elemento otro, extraño y deslocalizador del propio suceso al que se está refiriendo. Unidos ambos elementos, la acción y la imitación, el resultado de la mímesis es la generación, como indica Ricoeur 
de una noesis práctica (Ricoeur, 2004: 86), es decir, una intelección que reposa previamente en una configuración activa por parte del poeta o del investigador.

Ahora bien, debemos de radicalizar esta noción de noesis práctica más allá del sentido original que encuentra Ricoeur en Aristóteles. Que nuestra labor como investigadores en el trabajo de campo pueda ser comparada con una mímesis bajo la fórmula de noesis práctica tiene que decir no solo que es una forma de intelección que implica en sí misma una acción, la composición de la trama poética o discursiva (hasta aquí llega Ricoeur). En su radicalización, la fórmula que quiero proponer es que este concepto tiene que significar una intelección sustentada por una acción presente en un mundo enteramente material y no exclusivamente simbólico. El tipo de noesis que mejor explica el trabajo de campo ha de ser más que una acción intelectual o discursiva, una acción volcada en ese espacio de cuerpos, objetos y también significados. Para resumir, entender el trabajo de campo como mímesis implica reconocer nuestro papel como reactualizadores y convocantes materiales de los fenómenos que queremos estudiar. Así obramos la radicalización de ese concepto de noesis práctica que nos prestaba Ricoeur.

En términos epistemológicos desde el cognitivismo situado se ha propuesto el concepto de realismo incorporado para explicar esta aspiración. El realismo incorporado no es el realismo tradicional que afirma la existencia de las cosas con independencia del sujeto cognoscente: es una postura epistemológica que afirma la realidad del medio, pero únicamente en la medida en que un cuerpo o un organismo se vincula pragmáticamente con él (Lakoff y Johnson 1999: 89-93). Solo existe esa posibilidad de realismo en tanto un investigador es capaz de actualizarla, convocarla y registrarla.

En nuestro caso, estas reflexiones nos llevan a concebir el trabajo de campo y nuestra labor como científicos sociales como una forma activa de recrear y distribuirnos mate- 
rialmente a través de los sucesos que queremos estudiar. A 1 respecto, serán decisivos los pasos que demos para la reactualización de los fenómenos. El que seamos capaces de revivir ciertos acontecimientos en unas determinadas locaciones va a ser sustantivo para el tipo de experiencias que se originen y el tipo de conocimiento que hagamos aparecer.

En virtud de lo anterior, mis éxitos y fracasos en la realización de la investigación de los fraccionamientos cerrados de clase alta en Guadalajara no se produjeron por una mayor o menor capacidad intelectiva o por una mayor o menor destreza en la acción posterior de la composición de mi relato; antes bien, se debieron fundamentalmente a las formas como pude incorporarme en la recreación de un campo de realidad. En esta medida, el recuento de las maniobras y afecciones por el campo no puede quedar como un apartado complementario a la presentación de los resultados en donde se dé cabida a la reflexividad. Dicho recuento debería ser trasversal a toda nuestra construcción del conocimiento en tanto que ambas, ejecución del campo y emergencia de los resultados, se efectuaron conjuntamente en una serie de emplazamientos concretos.

Fecha de recepcion: 04 de septiembre de 2013

Fecha de aceptacion: 28 de abril de 2014

Bibliografía

Aull Davis, Charlotte, 1999, Reflexive Ethnography: a Guide to Researching Selves and Others, Routledge, Londres.

Baudrillard, Jean, 1978, Cultura y simulacro, Kairós, Barcelona. Barthes, Roland, 1987, El susurro del lenguaje: más allá de la palabra y la escritura, Paidós, Barcelona.

Bourdieu, Pierre, Jean-Claude Chamboredon y Jean-Claude Passeron, 1975, El oficio del sociólogo, Siglo XXI, Buenos Aires. 
Confesiones de un médium. Hacia la materialización del trabajo de campo

Calonge Reillo, Fernando, 2013, Los sentidos de la ciudad. Sobre cómo mujeres y hombres ordenan sus espacios vitales, Universidad de Guadalajara, Guadalajara.

Csordas, Thomas J., 2007, "Transmutation of Sensibilities. Empathy, Intuition, Revelation”, en Athena McLean y Annett Leibing (eds.), The Shadow Side of Fieldword: Exploring the Blurred Borders Between Ethnography and Life, Blackwell, Oxford.

Gadamer, Hans George, 1977, Verdad y método, Ediciones Sígueme, Salamanca.

Giddens, Anthony, 1993, Las nuevas reglas del método sociológico, Amorrortu, Buenos Aires.

Habermas, Jürgen, 1988, La lógica de las ciencias sociales, Cátedra, Madrid.

Hesiodo, 1979, Los trabajos y los días, Universidad Autónoma de México, México.

James,Wendy, 1973,“'The Anthropologist as Reluctant Imperialist”, en Talal Asad (ed.), Anthropology and the Colonial Encounter, Ithaca Press, Londres.

Johnson, Mark y Tim Rohrer, 2007,"We are Live Creatures: Embodiment, American Pragmatism and the Cognitive Organism”, en Tom Ziemke et ál., Body, Language and Mind.Volume I:Embodiment, Mouton de Gruyter, Berlín.

Lakoff, George y Mark Johnson, 1986, Metáforas de la vida cotidiana, Cátedra, Madrid.

, 1999, Philosophy in the Flesh: the Embodied Mind and its Challenge to Western Though, Basic Books, Nueva York.

Latour, Bruno, 1992, Ciencia en acción, Editorial Labor, Barcelona.

, 2002, La esperanza de Pandora, Gedisa, Barcelona.

, 2005, Reensamblar lo social, Manantial, Barcelona.

Teoría y DEBATE No. 60 
Fernando Calonge Reillo

Bibliografía | Leslie, Helen y Donovan Storey, 2003, "Entering the Field”, en Regina Scheyvens y Donovan Storey (eds.), Developing Fieldwork, Sage, Londres.

Maturana, Humberto y Francisco Varela, 1984, El árbol del conocimiento. Las bases biológicas del entendimiento humano, Lumen, Buenos Aires.

MacPherson, C. B., 1970, La teoría política del individualismo posesivo, Fontanella, Barcelona.

Real Academia Española, 200I, Diccionario de la Real Academia Española, Madrid, Espasa Libros.

Ricoeur, Paul, 2004, Tiempo y narración. I Configuración del tiempo en el relato histórico, Siglo XXI, Buenos Aires.

Rorty, Richard, 1995, La filosofia y el espejo de la naturaleza, Cátedra, Madrid.

Sibeud, Emmanuelle, 2008, "The Metamorphosis of Ethnology in France, I839-1930”, en Henrika Kucklik (ed.), A New History of Anthropology, Blackwell, Oxford.

Voloshinov, Valentin, 1976, El signo ideológico y la filosofia del lenguaje, Ediciones Nueva Visión, Buenos Aires. 